\title{
INOVASI RANCANGAN MOBILE PIG RECEIVER UNTUK DIAMETER PIPELINE 10” SAMPAI 16”
}

\author{
Agus Edy Pramono ${ }^{1}$, Eric Guntur Wibowo \\ Jurusan Teknik Mesin, Politeknik Negeri Jakarta, Kampus Baru UI Depok, 16424 \\ e-mail :1agus.edypramono@mesin.pnj.ac.id
}

\begin{abstract}
Pigging process done to clean pipeline from water, waste, or residue from the result of welding on pipeline. The quality of gas distributed it would affect if there are remaining residue in the pipeline. The pipeline will also faster rusty if there water left in the pipeline, the corrosion on the pipe can be determined according to the corrosion coupon attached to the pipeline. After pigging process or cleaning done, pig receiver would not be used until the next process pigging or cleaning. Because this arise the idea of design pig receiver with eccentric reducer which can be replaced so pig receiver can be used on another size pipeline at a same plant or same station. This device consist of main shell that used to store pig which come from pipeline and eccentric reducer to adapt pipeline size with main shell. This device equipped with locking mechanism using thread at top and bottom that operated manually. This mechanism used to lock up the vessel lid and eccentric reducer that is connected to main shell, so operator can easily open the vessel lid and replace eccentric reducer according to needs. In this design the pig receiver design made for gas pipeline with maximum operasional pressure 660 [psig], pipeline diameter size 10" to 16" with 18" main shell diameter.
\end{abstract}

Key words : Pig receiver, eccentric reducer, pigging, size.

\begin{abstract}
ABSTRAK
Proses pigging dilakukan untuk membersihkan jalur pipa dari air, kotoran, maupun sisa hasil pengelasan pada sambungan jalur pipa. Kualitas gas yang didistribusikan akan berpengaruh jika ada kotoran yang tersisa di dalam jalur pipa. Jalur pipa juga akan lebih cepat berkarat jika ada air yang tertinggal di dalam jalur pipa, laju korosi pada jalur pipa dapat ditentukan dari hasil pengamatan corrosion coupon yang dipasang pada jalur pipa. Setelah proses pigging atau pembersihan dilakukan, pig receiver tidak akan digunakan sampai proses pigging atau pembersihan berikutnya. Oleh sebab itu timbul gagasan untuk merancang pig receiver dengan eccentric reducer yang dapat diganti sehingga pig receiver dapat digunakan pada ukuran jalur pipa lainnya pada sebuah plant atau station yang sama. Alat ini terdiri dari main shell yang berfungsi sebagai tempat menyimpan pig yang datang dari pipeline dan eccentric reducer untuk menyesuaikan ukuran pipeline dengan main shell. Alat ini dilengkapi dengan mekanisme penguncian menggunakan ulir transmisi pada bagian atas dan bawah yang dioperasikan secara manual. Mekanisme ini digunakan untuk mengunci tutup bejana dan eccentric reducer yang terhubung pada main shell, sehingga operator dapat dengan mudah membuka tutup bejana dan dapat mengganti eccentric reducer sesuai kebutuhan. Dalam rancangan ini dibuat desain Pig Receiver untuk pipa gas dengan tekanan operasional maksimum 660 [psig], diameter jalur pipa sebesar 10" sampai 16" dengan diameter mayor shell adalah 18".
\end{abstract}

Katakunsi : Pig receiver, eccentric reducer, pigging, ukuran.

\section{PENDAHULUAN}

Proses pigging merupakan proses pembersihan pipeline dengan meluncurkan pig dari pig launcher ke pig receiver. Proses ini dilakukan untuk membersihkan pipeline dari kotoran dan air yang tertinggal di dalam pipa. Pigging atau pembersihan rutin dilakukan dalam waktu tertentu, untuk menjaga pipeline dari korosi maupun kerusakan lainnya. Jadwal pigging atau pembersihan dapat ditentukan dari hasil pengamatan corrosion coupon yang dipasang pada pipeline.

Gas yang mengalir pada pipeline tidak akan melewati pig launcher maupun pig receiver ketika pigging dilakukan. Setelah proses pigging, pig receiver 
tidak digunakan sampai proses berikutnya. Pig receiver yang sudah ada saat ini tidak dapat digunakan pada pipeline dengan diameter berbeda karena memiliki eccentric reducer yang permanen.

Oleh karena itu, timbul gagasan merancang pig receiver sebagai penerima pig pada proses pigging yang mampu menahan tekanan operasional gas sebesar 660 [psi] dengan mekanisme penutup bejana menggunakan ulir dan eccentric reducer yang dapat diganti menggunakan mekanisme ulir, sehingga pig receiver dapat digunakan pada pipeline yang berukuran 10" sampai 16".

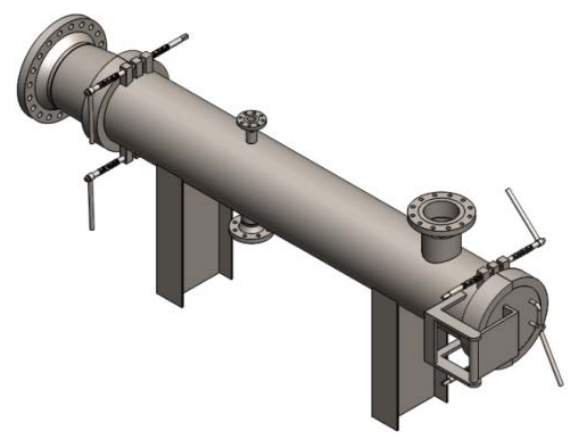

Gambar1. Rancangan Pig Receiver

\section{METODE PENELITIAN}

Metode yang digunakan dalam perancangan ini berdasarkan Gambar.2 adalah dengan melakukan observasi. Pada tahap observasi ditemukan masalah yang terjadi di lapangan, pig receiver yang ada pada plant yang diobservasi tidak digunakan lagi setelah proses pigging sampai proses pigging berikutnya. Hal ini menyebabkan pig receiver tidak dioperasikan dalam jangka waktu dekat. Selanjutnya dilakukan studi literatur dan kajian pustaka sebagai referensi agar didapat solusi terbaik dari masalah yang ditemukan. Data yang didapatkan dari hasil observasi diolah agar didapatkan spesifikasi yang sesuai dengan kebutuhan. Tahap selanjutnya adalah membuat rancangan sekaligus melakukan analisa pada alat yang dirancang untuk mengetahui berbagai kemungkinan yang akan terjadi pada alat serta menentukan spesifikasi komponen mana yang paling tepat untuk diterapkan pada rancangan.

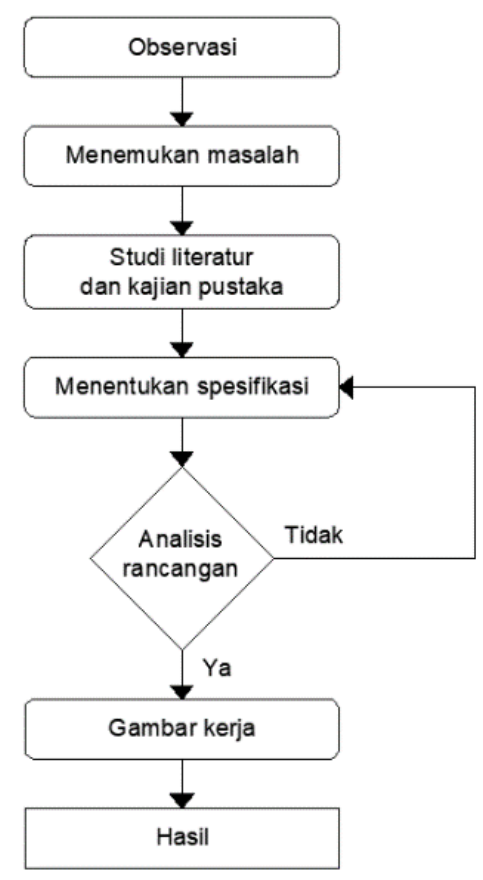

Gambar 2. Diagram Alur Metode Perancangan

Dalam rancangan ini ditetapkan tekanan operasional gas maksimum sebesar 660 [psi]

Tekanan Operasional Gas = 660 [psi] Tekanan Desain Gas lebih besar 10\% dari Tekanan Operasional [1]

Tekanan Desain Gas = Tekanan

Operasional $+10 \%$ Tekanan

Operasional

Tekanan Desain Gas $=660[\mathrm{psi}]+66$

[psi] $=726$ [psi $]$

1 [psi $]=6894,7572[\mathrm{~Pa}]$

$726 \times 6894,7572=5005593,727[\mathrm{~Pa}] \approx$ $5,005[\mathrm{MPa}]$

Jadi Tekanan Desain Gas $=$ 5,005

[MPa]. 
Untuk menentukan nilai dari laju korosi dapat melihat tabel standar kualitas pada laju korosi berikut [3]:

Tabel 1. Kualitas laju korosi

\begin{tabular}{|c|c|}
\hline \multicolumn{2}{|c|}{$\begin{array}{c}\text { Approximate metric } \\
\text { equivalent }\end{array}$} \\
\hline $\begin{array}{c}\text { Relative } \\
\text { corrosion }\end{array}$ & $\frac{\boldsymbol{m m}}{\boldsymbol{y r}}$ \\
resistance* & $<0,02$ \\
\hline Outstanding & $<0,1$ \\
Excellent & $0,02-0,1$ \\
Good & $0,1-0,5$ \\
Fair & $0,5-1$ \\
Poor & $1-5$ \\
Unacceptable & $5+$ \\
\hline
\end{tabular}

Tabung utama berfungsi menampung air dan kotoran serta pig foam yang diluncurkan dari pig launcher. Diameter yang digunakan untuk shell/tabung utama adalah 457 [mm]/18 [inch]. Berikut perhitungan untuk mendapatkan ketebalan shell/tabung utama:

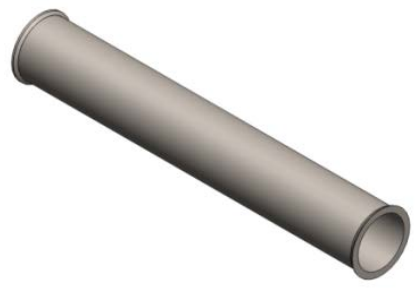

Gambar 3. Tabung utama

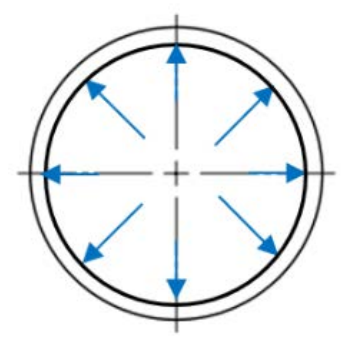

Gambar 4. Gaya yang bekerja terhadap Tabung utama

Digunakan Material A 106 Gr B dengan yield strength :

$\sigma_{\mathrm{y}}=35000[\mathrm{psi}] \approx 241,315[\mathrm{MPa}]$

$\bar{\sigma}=\frac{\sigma_{\mathrm{y}}}{\text { Angka } \operatorname{aman}}=\frac{241,315[\mathrm{MPa}]}{4}$
Ketebalan Tabung Utama dihitung dengan effisiensi sambungan pipa seamless $=1[1]$

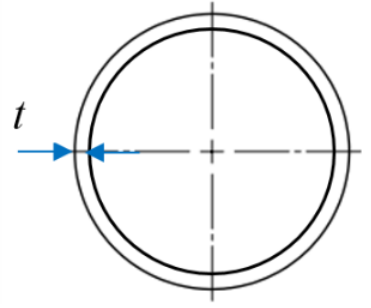

Gambar 5. Ketebalan tabung utama

$$
\begin{aligned}
& t=\frac{\mathrm{P} \cdot \mathrm{R}}{\bar{\sigma} \cdot \mathrm{E}+0,4 \mathrm{P}} \\
& =\frac{5,005[\mathrm{MPa}] \cdot 228,5[\mathrm{~mm}]}{60,328[\mathrm{MPa}] \cdot 1+0,4 \cdot 5,005[\mathrm{MPa}]} \\
& t=18,3481[\mathrm{~mm}]
\end{aligned}
$$

Laju korosi = 0,1 [mm/tahun] $($ Tabel 1) Desain alat untuk 20 tahun sehingga, [3] Laju Korosi $=0,1[\mathrm{~mm} /$ tahun $] \times 20$

$$
\text { [tahun] }
$$$$
=2[\mathrm{~mm}]
$$

Tebal Shell $=\mathrm{t}+$ Laju Korosi

$$
\begin{aligned}
& =18,3481[\mathrm{~mm}]+2[\mathrm{~mm}] \\
& =20,3481[\mathrm{~mm}]
\end{aligned}
$$

Tabung utama menggunakan pipa diameter 457 [mm]/18 [inch] dengan schedule 80, tebal pipa 23,83 [mm] sesuai dengan katalog standart.

Pipa vent berada pada bagian atas pig receiver fungsinya ialah untuk membuang gas pada saat pig receiver dalam perawatan. Untuk pipa vent digunakan ukuran pipa 60,3 [mm]/2 [inch]. Berikut perhitungan untuk mendapatkan ketebalan dari pipa vent

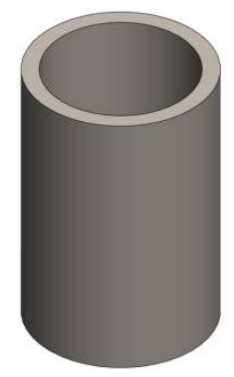

Gambar 6. Pipa vent 


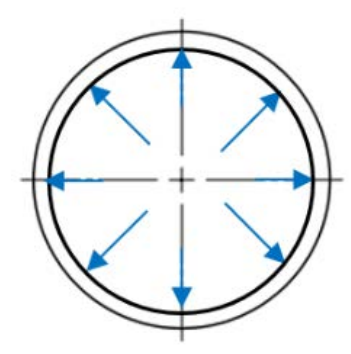

Gambar 7. Gaya yang bekerja pada Pipa vent

$\sigma_{\mathrm{y}}=35000[\mathrm{psi}] \approx 241,315[\mathrm{MPa}]$

$\bar{\sigma}=\frac{\sigma_{\mathrm{y}}}{\text { Angka aman }}=\frac{241,315[\mathrm{MPa}]}{4}$

$\bar{\sigma}=60,328[\mathrm{MPa}]$

Ketebalan Pipa Vent dihitung dengan effisiensi sambungan pipa seamless $=1$ [1].

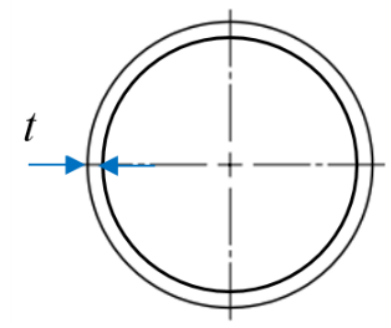

Gambar 8. Ketebalan pipa vent

$t=\frac{\mathrm{P} \cdot \mathrm{R}}{\bar{\sigma} \cdot \mathrm{E}+0,4 \mathrm{P}}$

$=\frac{5,005[\mathrm{MPa}] \cdot 30,15[\mathrm{~mm}]}{60,328[\mathrm{MPa}] \cdot 1+0,4 \cdot 5,005[\mathrm{MPa}]}$

$t=2,4209[\mathrm{~mm}]$

Laju korosi $=0,1$ [mm/tahun] (Tabel 1) Desain alat untuk 20 tahun sehingga, [3] Laju Korosi $=0,1[\mathrm{~mm} /$ tahun $] \times 20$ [tahun]

$$
=2[\mathrm{~mm}]
$$

Tebal Shell $=\mathrm{t}+$ Laju Korosi

$$
\begin{aligned}
& =2,4209[\mathrm{~mm}]+2[\mathrm{~mm}] \\
& =4,4209[\mathrm{~mm}]
\end{aligned}
$$

Pipa vent menggunakan pipa diameter $60,3[\mathrm{~mm}] / 2$ [inch] dengan schedule 80 , tebal pipa 5,54 [mm] sesuai dengan katalog standart.
Pipa drain berada pada bagian bawah pig receiver fungsinya ialah untuk membuang air yang tertampung pada pig receiver. Untuk pipa drain digunakan ukuran pipa 114,3 [mm]/4 [inch]. Berikut perhitungan untuk mendapatkan ketebalan dari pipa drain :

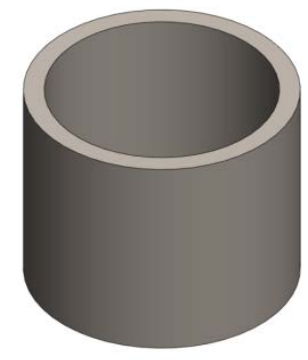

Gambar 9. Pipa drain

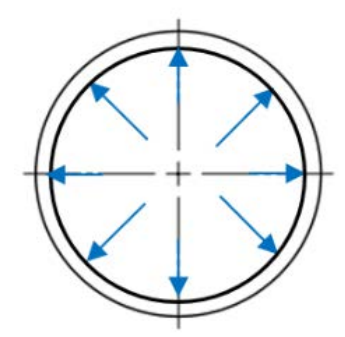

Gambar 10. Gaya yang bekerja terhadap Pipa drain

Digunakan Material A 106 Gr B dengan yield strength :

$\sigma_{\mathrm{y}}=35000[\mathrm{psi}] \approx 241,315[\mathrm{MPa}]$

$\bar{\sigma}=\frac{\sigma_{\mathrm{y}}}{\text { Angka } \operatorname{aman}}=\frac{241,315[\mathrm{MPa}]}{4}$

$\bar{\sigma}=60,328[\mathrm{MPa}]$

Ketebalan Pipa Drain dihitung dengan effisiensi sambungan pipa seamless $=1$ [1].

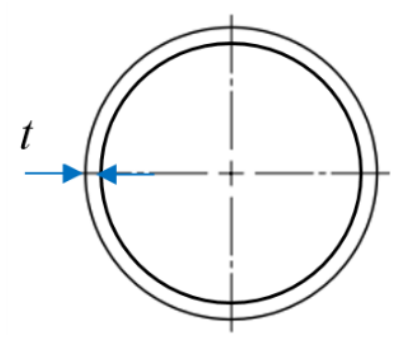

Gambar 11. Ketebalan pipa drain

$t=\frac{\mathrm{P} \cdot \mathrm{R}}{\bar{\sigma} \cdot \mathrm{E}+0,4 \mathrm{P}}$ 
$=\frac{5,005[\mathrm{MPa}] \cdot 57,15[\mathrm{~mm}]}{60,328[\mathrm{MPa}] \cdot 1+0,4 \cdot 5,005[\mathrm{MPa}]}$

$t=4,5890[\mathrm{~mm}]$

Laju korosi $=0,1[\mathrm{~mm} /$ tahun $]($ Tabel 1$)$ Desain alat untuk 20 tahun sehingga, [3] Laju Korosi $=0,1[\mathrm{~mm} /$ tahun $] \times 20$ [tahun]

$$
=2[\mathrm{~mm}]
$$

Tebal Shell $=\mathrm{t}+$ Laju Korosi

$$
\begin{aligned}
& =4,5890[\mathrm{~mm}]+2[\mathrm{~mm}] \\
& =6,5890[\mathrm{~mm}]
\end{aligned}
$$

Pipa drain menggunakan pipa diameter $114,3[\mathrm{~mm}] / 4$ [inch] dengan schedule 80, tebal pipa 8,56 [mm] sesuai dengan katalog standart.

\section{Tutup Bejana Tekan}

Diameter Tutup dibuat lebih besar dari diameter shell sebesar $508[\mathrm{~mm}] / 20$ [inch] agar dapat menekan permukaan gasket.

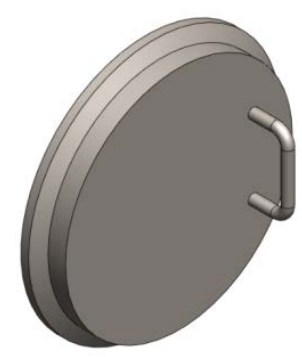

Gambar12. Tutup bejana tekan

Digunakan Material A 106 Gr B dengan yield strength :

$$
\begin{aligned}
& \sigma_{\mathrm{y}}=35000[\mathrm{psi}] \approx 241,315[\mathrm{MPa}] \\
& \bar{\sigma}=\frac{\sigma_{\mathrm{y}}}{\text { Angka aman }}=\frac{241,315[\mathrm{MPa}]}{4} \\
& \bar{\sigma}=60,328[\mathrm{MPa}]
\end{aligned}
$$

Maka tebal tutup bejana dapat dihitung [1] :

$$
\begin{aligned}
& t=\mathrm{d} \sqrt{0,3 \times \frac{P}{\bar{\sigma}}} \\
& =508[\mathrm{~mm}] \sqrt{0,3 \times \frac{5,005}{60,328}}
\end{aligned}
$$

$$
t=80,1432[\mathrm{~mm}]
$$

Laju korosi $=0,1[\mathrm{~mm} /$ tahun $]($ Tabel 1$)$ Desain alat untuk 20 tahun sehingga, [3] Laju Korosi $=0,1[\mathrm{~mm} /$ tahun $] \times 20$ [tahun]

$$
=2[\mathrm{~mm}]
$$

Tebal Shell $=\mathrm{t}+$ Laju Korosi

$$
\begin{aligned}
& =80,1432[\mathrm{~mm}]+2[\mathrm{~mm}] \\
& =82,1432[\mathrm{~mm}]
\end{aligned}
$$

Gaya yang bekerja pada tutup shell $\mathrm{R}$ tutup $=10$ [inch $]$

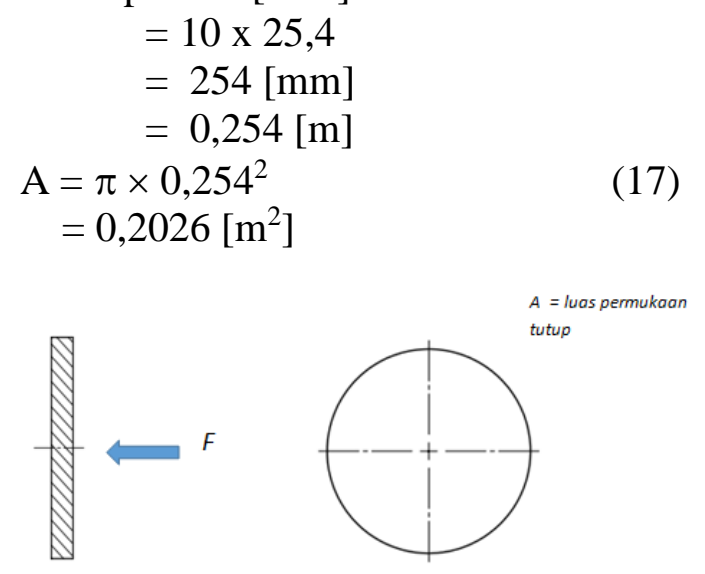

Gambar 13. Gaya yang terjadi pada tutup

$$
\begin{aligned}
P & =\frac{\mathrm{F}}{\mathrm{A}} \\
\mathrm{F} & =\mathrm{P} \times \mathrm{A} \\
& =5005593,727[\mathrm{~Pa}] \times 0,2026\left[\mathrm{~m}^{2}\right] \\
& =1014133,289[\mathrm{~N}]
\end{aligned}
$$

Gaya yang diterima oleh tutup diterima pengunci, pada permukaan yang memiliki kemiringan $30^{\circ}$.

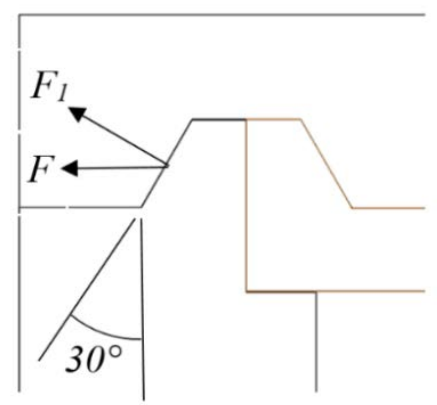

Gambar 14. Gaya yang terjadi antara tutup dengan pengunci

$\mathrm{F}_{1}=\mathrm{F} \cos 30^{\circ}$

$\mathrm{F}_{1}=1014133,289[\mathrm{~N}] \cos 30^{\circ}$

$$
=878265,191[\mathrm{~N}]
$$


Sebagai reaksi yang menahan gaya $F_{1}$ dibutuhkan gaya pengunci.

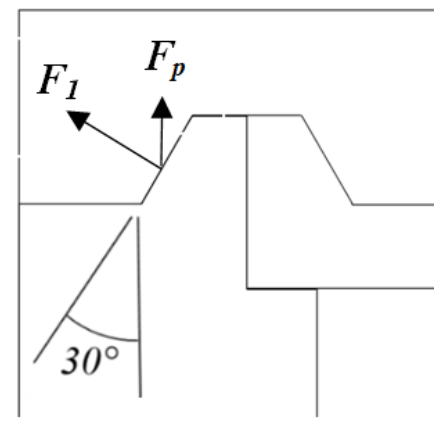

Gambar 15. Gaya yang dibutuhkan untuk mengunci tutup

$\mathrm{F}_{\mathrm{p}}=\mathrm{F}_{1} \sin 30^{\circ}$

$F_{p}=878265,191[N] \sin 30^{\circ}$

$$
=439132,595[\mathrm{~N}]
$$

Gaya yang dibutuhkan setiap pengunci untuk mengunci tutup bejana ialah sebesar.

$\mathrm{F}_{\text {operasional }}=\frac{\mathrm{F}_{\mathrm{p}}}{\text { Jumlah pengunci }}$

$\mathrm{F}_{\text {operasional }}=\frac{439132,595[\mathrm{~N}]}{2}$

$\mathrm{F}_{\text {operasional }}=219566,297[\mathrm{~N}]$

\section{Ulir Gerak}

Pada ulir gerak digunakan jenis material High Carbon Steel AISI 1080 dengan yield strength :

$\sigma_{\mathrm{y}}=586,054[\mathrm{MPa}]$

$$
\bar{\sigma}=\frac{\sigma_{\mathrm{y}}}{\text { Angka } \operatorname{aman}}=\frac{586,054[\mathrm{MPa}]}{4}
$$

$\bar{\sigma}=146,513[\mathrm{MPa}]$

$\rho=7800\left[\mathrm{Kg} / \mathrm{m}^{3}\right]$

Diameter minor ulir kotak [2]:

$\tau_{\text {tarik }}=\frac{\mathrm{F}}{\mathrm{A}}$

$\tau_{\text {tarik }}=\frac{\mathrm{F}}{\frac{\pi}{4} \times \mathrm{D}^{2}}$

$$
\begin{aligned}
& D=\sqrt{\frac{4 \times \mathrm{F}}{\pi \times \bar{\sigma}}} \\
& D=\sqrt{\frac{4 \times 219566,297[\mathrm{~N}]}{\pi \times 146,513[\mathrm{MPa}]}} \\
& D=43,68[\mathrm{~mm}]
\end{aligned}
$$

\begin{tabular}{|c|c|c|c|c|c|c|c|}
\hline \multirow{2}{*}{$\begin{array}{c}\text { Nominal } \\
\text { Diameter } \\
\quad\left(d_{1}\right)\end{array}$} & \multicolumn{2}{|c|}{ Major Diameter } & \multirow{2}{*}{$\begin{array}{c}\text { Minor } \\
\text { Diameter } \\
\quad\left(d_{c}\right)\end{array}$} & \multirow{2}{*}{$\begin{array}{c}\text { Pitch } \\
(p)\end{array}$} & \multicolumn{2}{|c|}{$\begin{array}{c}\text { Depth Of } \\
\text { Thread }\end{array}$} & \multirow{2}{*}{$\begin{array}{c}\text { Area } \\
\text { Of } \\
\text { Core } \\
\left(A_{c}\right) \\
\mathrm{mm}^{2}\end{array}$} \\
\hline & $\begin{array}{l}\text { Bolt } \\
\text { (d) }\end{array}$ & $\begin{array}{l}\text { Nut } \\
\text { (D) }\end{array}$ & & & $\begin{array}{l}\text { Bolt } \\
\text { (h) }\end{array}$ & $\begin{array}{l}\text { Nut } \\
\text { (H) }\end{array}$ & \\
\hline 22 & 22 & 22,5 & 17 & \multirow{4}{*}{5} & \multirow{4}{*}{2,5} & \multirow{4}{*}{2,75} & 227 \\
\hline 24 & 24 & 24,5 & 19 & & & & 284 \\
\hline 26 & 26 & 26,5 & 21 & & & & 346 \\
\hline 28 & 28 & 28,5 & 23 & & & & 415 \\
\hline 30 & 30 & 30,5 & 24 & \multirow{4}{*}{6} & \multirow{4}{*}{3} & \multirow{4}{*}{3,25} & 452 \\
\hline 32 & 32 & 32,5 & 26 & & & & 531 \\
\hline 34 & 34 & 34,5 & 28 & & & & 616 \\
\hline 36 & 36 & 36,5 & 30 & & & & 707 \\
\hline 38 & 38 & 38,5 & 31 & \multirow{4}{*}{7} & \multirow{4}{*}{3,5} & \multirow{4}{*}{3,75} & 755 \\
\hline 40 & 40 & 40,5 & 33 & & & & 855 \\
\hline 42 & 42 & 42,5 & 35 & & & & 962 \\
\hline 44 & 44 & 44,5 & 37 & & & & 1075 \\
\hline 46 & 38 & 38,5 & 38 & \multirow{4}{*}{8} & \multirow{4}{*}{4} & \multirow{4}{*}{4,25} & 1134 \\
\hline 48 & 40 & 40,5 & 40 & & & & 1257 \\
\hline 50 & 42 & 42,5 & 42 & & & & 1385 \\
\hline 52 & 44 & 44,5 & 44 & & & & 1521 \\
\hline 55 & 55 & 55,5 & 46 & \multirow{4}{*}{9} & \multirow{4}{*}{4,5} & \multirow{4}{*}{5,25} & 1662 \\
\hline 58 & 58 & 58,5 & 49 & & & & 1886 \\
\hline 60 & 60 & 60,5 & 51 & & & & 2043 \\
\hline 62 & 62 & 62,5 & 53 & & & & 2206 \\
\hline
\end{tabular}

Tabel 2. Dimensi Utama Square Thread [mm](Normal Series)

Menurut IS: 4694-1968 (Reaffirmed 1996)

Berdasarkan Tabel 2, maka didapat spesifikasi seperti berikut:

- Diameter Nomimal = $52[\mathrm{~mm}]$

- Diameter Mayor :

o $\quad$ Bolt $=44[\mathrm{~mm}]$

o $\quad$ Nut $=44,5[\mathrm{~mm}]$

- $\quad$ Diameter Minor $=44[\mathrm{~mm}]$

- Pitch $=8$ [mm]

- Kedalaman Screw : oBolt $=4[\mathrm{~mm}]$ oNut $=4,25[\mathrm{~mm}]$

- $\quad$ Area Core $=1521\left[\mathrm{~mm}^{2}\right]$

Tegangan yang terjadi pada ulir gerak [6]:

$$
\sigma_{\text {tekan }}=\frac{\mathrm{W}}{\mathrm{A}_{\mathrm{c}}}
$$




$$
\begin{gathered}
\sigma_{\text {tekan }}=\frac{4 . \mathrm{W}}{\pi \cdot \mathrm{d}_{\mathrm{c}}^{2}} \\
\sigma_{\text {tekan }}=\frac{4.219566,297[\mathrm{~N}]}{\pi(44[\mathrm{~mm}])^{2}} \\
\sigma_{\text {tekan }}=144,401[\mathrm{~N}]
\end{gathered}
$$

\section{HASIL dan PEMBAHASAN}

Rancangan pig receiver dirancang berdasarkan data-data yang telah diperoleh dari hasil analisis. Desain rancangan pig receiver ini terdiri dari komponen sebagai berikut.

Tabung Utama

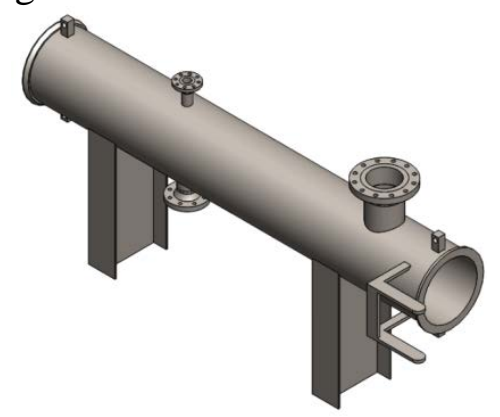

Gambar 6. Tabung Utama

Tabung utama sebagai tempat menerima pig, kotoran, maupun partikel lainnya yang saat pembersihan pipeline atau pigging.

Pengunci

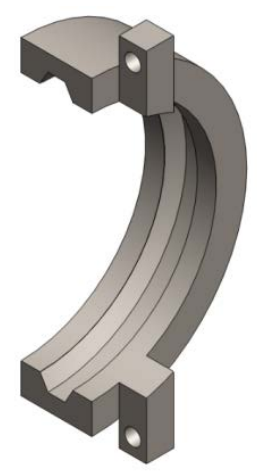

Gambar 7. Pengunci

Pengunci pada Gambar 7 berfungsi untuk mengunci tutup bejana dan eccentric reducer pada bagian kiri dan kanan.

Poros Berulir

Poros berulir berfungsi untuk mengencangkan kedua pengunci agar dapat menahan tekanan dari dalam bejana.

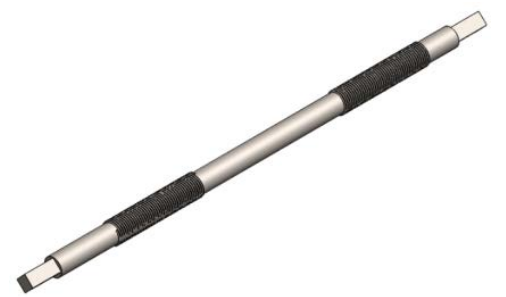

Gambar 8. Poros Berulir

Tutup Bejana

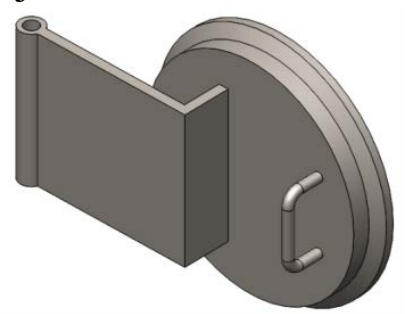

Gambar 9. Tutup Bejana

Tuas Pengunci

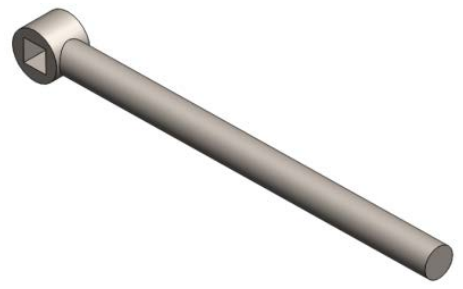

Gambar 10. Tuas Pengunci

Tuas pengunci digunakan untuk membantu operator melakukan penguncian.

Prinsip Kerja Alat

Pig receiver yang akan dirancang merupakan alat untuk menerima pig dari gas pipeline yang memiliki tekanan operasional maksimum sebesar 660 [psi] yang memiliki mekanisme pengunci tutup bejana menggunakan poros berulir pada bagian atas dan bawah. Eccentric reducer yang dipasang menggunakan mekanisme penguncian yang dengan tutup bejana, sehingga dapat diganti sesuai dengan kebutuhan.

\section{KESIMPULAN}

Simpulan yang dapat diambil dari rancangan pig receiver ini adalah Rancangan pig receiver mampu beroperasi pada tekanan operasional 
maksimum gas pada 660 [psi] dengan panjang 3000 [mm]. Tabung utama memiliki diameter sebesar 18 [inch] dengan ketebalan sebesar 23,83 [mm]. Tutup bejana memiliki diameter sebesar 20 [inch] dengan ketebalan sebesar 82,14 [mm].

\section{UCAPAN TERIMA KASIH}

Ucapan terima kasih disampaikan kepada PT. PUSTEK E\&T yang telah bersedia menyediakan data dan membantu observasi penelitian.

\section{DAFTAR PUSTAKA}

[1] Eugene F. Megyesy. 1973. Pressure Vessel Handbook. Tulsa Oklahoma : Pressure Vessel Publishing.

[2] Khurmi, R.S. dan J.K Gupta. 2015. A Textbook of Machine Design. New Delhi : Eurasia Publishing House (PVT.) LTD.

[3] Mars G. Fontana. 1987. Corrosion Engineering Third Edition. New York : McGraw-Hill Company.

[4] Pramono A.E., 2013. Buku Ajar Elemen Mesin I.Jakarta.

[5] Pramono A.E., 2015. Buku Ajar Elemen Mesin II.Jakarta. 